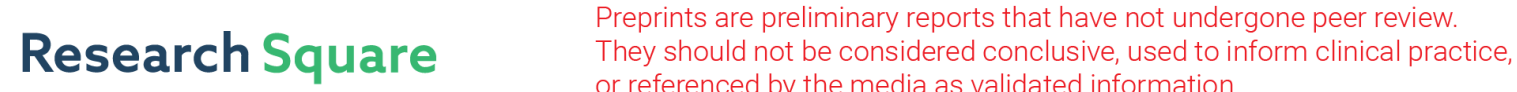 or referenced by the media as validated information. \\ Investigation on the Correlation Between Humanistic Care Ability and Emotional Intelligence of Hospital Staff
}

\section{Jingjing Ma}

Sichuan University

Wentao Peng (D 670537614@qq.com )

Sichuan University

Jihong Pan

Sichuan University

\section{Research Article}

Keywords: hospital staff, emotional intelligence, humanistic care ability

Posted Date: July 15th, 2021

DOl: https://doi.org/10.21203/rs.3.rs-707688/v1

License: (c) (i) This work is licensed under a Creative Commons Attribution 4.0 International License.

Read Full License 


\section{Abstract}

Background: There are different degrees of flaws in the knowledge structure of humanistic medicine of medical staff. The level of emotional intelligence of medical staff affects their career development as well as the doctor-patient relationship. Currently, there is a scarcity of relevant literature on the humanistic care ability and emotional intelligence of medical staff at home and abroad. Here, we tried to investigate this aspect of healthcare.

Methods: A cross-sectional study was conducted among the staff of West China Second University Hospital Sichuan University in April 2020. We used the Caring Ability Inventory (CAI) and Wong and Law Emotional Intelligence Scale (WLEIS) to conduct this analysis.

Results: A total of 3641 questionnaires were distributed, and 769 (21.12\%) were recovered. The total average score of the humanistic care ability of hospital staff was (197.77 \pm 20.30$)$, which was lower than the international norm. The total average score of emotional intelligence was $(84.21 \pm 13.48)$. The CAI score was higher in females than in males; the scores of CAI and WLEIS of the students who choose their own major because of their own interests were higher than those of other reasons; the scores of CAl and WLEIS of those who had received more comprehensive and in-depth humanistic care training were higher than those who had not; the CAl scores of those who had participated in volunteer service activities were higher than those who had not; the WLEIS score of the pediatric staff was higher than that of outpatient and emergency staff, and the differences were statistically significant $(P<0.05)$. Pearson correlation analysis showed that the total score of emotional intelligence, self-emotion evaluation and expression, self-emotion management, self-emotion application, recognition of other's emotions, and humanistic care ability of hospital staff were positively correlated $(P<0.001)$.

Conclusion: The development of internal factors of emotional intelligence of hospital staff was unbalanced, and humanistic care ability was at a lower level. Emotional intelligence was positively correlated to humanistic care ability.

\section{Background}

"Care" is an important concept in the healthcare profession (1), which refers to the internal accomplishment acquired by individuals through cognition, practice, and education, which integrates knowledge, attitude, emotion, and behavior, and at the same time it externalizes into the actual ability of consciously serving patients (2). Care, a necessary personality and psychological trait of medical staff, is an important quality of the medical staff. It can change the living conditions of patients, improve their quality of life, and improve the satisfaction of patients. A survey of medical staff (3) showed that there were different degrees of defects in the knowledge structure of humanistic medicine among the medical staff; the teaching effect of humanistic medicine on the academic education stage was not found to be ideal in medical practice, the continuing education of humanistic medicine was insufficient, the mastery of humanistic knowledge was poor, the structure of humanistic knowledge was distinct from practice, 
and there were many types of construction obstacles. Additionally, humanistic care ability (HCA) is also challenged and influenced by many factors, such as personal character, social support, psychological characteristics, and work-related factors (4), which make it difficult for the medical education to implement HCA training.

Emotional intelligence refers to the ability of an individual to monitor his or her as well as other's emotions and to use this information to guide his or her own thoughts and behavior (5). Salovey and Mayer defined emotional intelligence as a subset of social intelligence, including monitoring his or her own and others' feelings and emotions (6). The ability to distinguish oneself from others and use this information to guide their thinking and action and the ability to identify, use, understand, and manage their emotions can bring better problem-solving ability in one's emotional life. In recent years, there has been a gradual increase in the investigation of emotional intelligence in management, leadership, organizational behavior, and other fields, and the influence of emotional intelligence on leadership, work pressure, work performance, turnover rate, self-concept, and other variables have been gradually confirmed (7). In the field of health care, Rochester et al. (8) pointed out that health professionals must understand their emotions and those of others and use this knowledge to cooperate with colleagues to effectively communicate with patients, cope with stress and uncertainty, and produce better treatment effects. Other studies (9) have also shown that the level of emotional intelligence of the medical staff affects their career development and the doctor-patient relationship. Individuals with higher emotional intelligence can better deal with high emotional work, and those with higher emotional intelligence are more likely to form a good doctor-patient and nurse-patient relationship. Weng $(10,11)$ showed that doctors with higher emotional intelligence could gain higher trust from patients. A study in South Korea (12) used the dimensions of emotional perception, emotional expression, and empathy in emotional intelligence for the prediction of the doctor-patient relationship. Compared with patients with negative emotions, such as irritability, anxiety, and depression, individuals with high emotional intelligence, could better respond, understand, and feel patients' inner emotional experience from the perspective of patients and were more likely to resonate with patients (13). In addition, apart from improving the doctor-patient communication and promoting the doctor-patient relationship, the cognitive and regulatory ability of emotional intelligence was also found to play an important role in improving the clinical diagnosis and treatment effect of doctors and promoting the health of patients (14). For clinical nurses, the perception of patients' emotions was the premise of exploring patients' needs. Nurses with higher emotional perceptions could easily avoid nurse-patient conflict. In addition, emotional intelligence was also found to be very critical for dealing with the relationship between stress and mental health. People with poor emotional control tended to refuse the help of family, friends, and others because of emotional problems and bore greater mental pressure (15).

At present, the investigation and research on HCA at home and abroad are mainly focused on medical college students, including medical students and nursing students $(16,17)$. There are also surveys on the HCA of clinicians and nurses in the literature, but they mainly focus on the HCA of clinical nurses. For example, Simmons and Cavanaugh (18) conducted a survey on the HCA of female nursing graduates in the United States; Hables (19), Xu et al. (20) conducted a CAl survey on nurses. In addition, there were 
also studies on the CAl evaluation of family caregivers of patients with chronic diseases abroad (21), but there are only a few studies on the HCA of doctors and none on the HCA of the whole hospital staff.

There are many studies on the emotional intelligence outside China, such as Cho et al. (22), Hiroshi and Kohsuke (23), and Li et al. (24), who conducted a survey on the emotional intelligence of undergraduates. Wan and Noor (25) conducted a study on the emotional intelligence of administrators. In the domestic medical and health field, literature reports mainly focus on the investigation or intervention of emotional intelligence of nurses or nursing students $(26,27)$, and some studies focus on the emotional intelligence of medical students (9). It can be seen that the research on the emotional intelligence of hospital staff at home and abroad is relatively rare. Based on this, this study focused on the whole hospital staff and investigated the HCA and emotional intelligence of hospital staff.

\section{Aims}

This study aimed to explore the status of HCA and emotional intelligence of the hospital staff, to explore the correlation analysis of the HCA of hospital staff, and to explore the relevant strategies to improve the HCA and emotional intelligence of the hospital staff.

\section{Methods}

\section{Design}

A cross-sectional survey was conducted in China in April 2020.

\section{Sample/Participants}

The staff of West China Second University Hospital Sichuan University, Sichuan Province, China, was selected as the research object. The West China Second Hospital, Sichuan University, which originated from Renji womens' hospital was established in 1896, is a tertiary grade-A hospital and is a national children's Regional Medical Center (southwest). It is mainly responsible for the treatment of critically ill women and children in cities of Sichuan Province, and even southwest China; the hospital had 1580 beds, 3641 staffs. Thus, although, this study included only one hospital, it was treated as a representative model.

\section{Variables and instruments}

A self-designed questionnaire, including gender, age, nationality, single child, religious belief, education background, occupation, marital status, professional title, Department, family residence, reasons for choosing the major, whether received training related to humanistic care, and whether participated in voluntary service activities.

Caring ability Inventory (CAl). CAl is a self-reported measurement method used to test a person's ability to care for others. The scale was developed by Nkongho; the tool has passed various reliability and validity 
tests and has been used in academic and clinical environments at home and abroad $(28,29)$. Ma Yulian, a Chinese scholar, translated the scale (30). The scale includes 3 dimensions and 37 items: knowledge (how well you know yourself, others, and your surroundings), courage (ability to handle unknown situations), and patience (endurance and toughness). Each dimension includes 14 items, 13 items, and 10 items, respectively. The Likert 7-level scoring method was used to score each response from "totally disagree" to "totally agree" with 1-7 points respectively, and some items were scored backwards. The Cronbach's a was 0.919 , the content validity index (CVI) was 0.957 , and the score ranged from 37 to 259 . The higher the score, the higher the HCA.

Wong and Law Emotional Intelligence Scale (WLEIS). WLEIS was developed in Hong Kong in 2002 by Huang (31); however, it has been used worldwide in many countries. Cross-cultural studies have been carried out, such as in Portugal (32), Japan (23), South Korea (33), etc. The Chinese version of WLEIS is also widely used in the Chinese mainland. WLEIS has four dimensions, four items in each dimension]; thus, a total of 16 items, including (34) self-emotion assessment and expression (refers to the ability of everyone to understand their deep emotions and express them naturally), self-emotion management (refers to the ability of people to regulate their emotions, so that they can recover from emotional fluctuations and anxiety more quickly), self-emotion management (refers to the ability of people to regulate their emotions, so that they can recover from emotional fluctuations and anxiety more quickly), self-emotion utilization (refers to the ability of individuals to use their emotions to guide themselves to constructive activities and personal performance), and emotion recognition of others (refers to the ability of individuals to perceive and understand the emotions of people around them). The Likert 7-level scoring method was used and 1-7 points were given from "completely disagree" to "completely agree," the internal consistency of each dimension was Cronbach's a $0.76 \sim 0.89$, and the score range was $16 \sim 112$. The higher the score, the higher was the level of emotional intelligence.

\section{Data collection}

The researchers developed a unified questionnaire filling instructions and guidelines, anonymously filled through the enterprise WeChat platform and answered online. The inclusion criteria included hospital staff, on-the-job workers, who knew and were willing to participate in the study, and the individuals who could not use smartphones/Internet were excluded. During research, the respondents gave informed consent, and the participants were informed of the subject and goal of the research. The researchers ensured the anonymity and confidentiality of the answers, and the rights and basic ethical principles of the participants in the whole process were guaranteed. A total of 3641 questionnaires were distributed, and 769 were returned, with a recovery rate of $21.12 \%$. Excluding the invalid questionnaires, such as incomplete answers and multiple choices, a total of 769 valid questionnaires were issued, with an effective rate of $100 \%$.

\section{Data analysis}

SPSS 22.0 statistical software was used for data processing. The data of CAI and WLEIS scores basically followed normal distribution, and the mean value from the $t$-test of independent samples was used to 
compare the two independent samples. ANOVA of independent samples was used to compare the two independent samples. LSD method was used to compare the two scales. Pearson correlation analysis was used to describe the correlation between the two scales. The bilateral test, $P<0.05$, implied that the difference was statistically significant.

\section{Results}

Socio-demographic characteristics of hospital staff

The average age of 769 hospital employees was $31.36 \pm 7.81 \mathrm{y}$. Table 1 shows other demographic characteristics.

Table 1. Socio-demographic characteristics of hospital staff $(n=769)$ 


\begin{tabular}{|c|c|c|}
\hline Variables & $\mathrm{n}$ & $\%$ \\
\hline \multicolumn{3}{|l|}{ Gender } \\
\hline male & 85 & 11.05 \\
\hline female & 684 & 88.95 \\
\hline \multicolumn{3}{|l|}{ Nation } \\
\hline Han nationality & 750 & 97.53 \\
\hline other & 19 & 2.47 \\
\hline \multicolumn{3}{|l|}{ Single child } \\
\hline no & 430 & 55.92 \\
\hline yes & 339 & 44.08 \\
\hline \multicolumn{3}{|l|}{ Religious beliefs } \\
\hline none & 760 & 98.83 \\
\hline yes & 9 & 1.17 \\
\hline \multicolumn{3}{|l|}{ Education } \\
\hline junior college & 107 & 13.91 \\
\hline undergraduate & 457 & 59.43 \\
\hline graduate student & 205 & 26.66 \\
\hline \multicolumn{3}{|l|}{ Occupation } \\
\hline nurse & 332 & 43.17 \\
\hline doctor & 148 & 19.25 \\
\hline technician & 187 & 24.32 \\
\hline other & 102 & 13.26 \\
\hline \multicolumn{3}{|l|}{ Marital status } \\
\hline married & 449 & 58.39 \\
\hline unmarried or divorced or widowed & 320 & 41.61 \\
\hline \multicolumn{3}{|l|}{ Title } \\
\hline junior title & 542 & 70.48 \\
\hline intermediate title & 183 & 23.80 \\
\hline deputy senior or senior professional title & 44 & 5.72 \\
\hline
\end{tabular}




\begin{tabular}{|c|c|c|}
\hline \multicolumn{3}{|l|}{ Department } \\
\hline pediatrics & 232 & 30.17 \\
\hline Obstetrics and Gynecology Department & 191 & 24.84 \\
\hline Outpatient and emergency department & 111 & 14.43 \\
\hline Medical Technology Department & 179 & 23.28 \\
\hline other & 56 & 7.28 \\
\hline \multicolumn{3}{|l|}{ Family residence } \\
\hline City or town & 536 & 69.70 \\
\hline Rural areas & 233 & 30.30 \\
\hline \multicolumn{3}{|l|}{ Reasons for choosing this major } \\
\hline Self-interest & 300 & 39.01 \\
\hline Easy to find a job & 83 & 10.79 \\
\hline Suggestions from family or others & 358 & 46.55 \\
\hline other & 28 & 3.64 \\
\hline \multicolumn{3}{|c|}{ Have you received training on humanistic care } \\
\hline No relevant training & 106 & 13.78 \\
\hline Less training & 515 & 66.97 \\
\hline More comprehensive and in-depth & 148 & 19.25 \\
\hline \multicolumn{3}{|c|}{ Have you ever participated in volunteer service } \\
\hline No & 208 & 27.05 \\
\hline Yes & 561 & 72.95 \\
\hline
\end{tabular}

\section{CAI and WLEIS scores of hospital staff}

The average score of WLEIS was $84.21 \pm 13.48$. The total average score of CAI was $197.77 \pm 20.3$, of which 332 nurses scored $198.71 \pm 18.73$. Compared with the international norms of nurse care ability (35), it was at a lower level (Table 2 and table 3 ).

Table 2. CAI and WLEIS scores of hospital staff $(n=769)()$ 
Items

average dimensions or items

\section{Humanistic care ability}

knowing

$78.25 \pm 9.77(5.59 \pm$

$0.70)$

CAI2- today is a society full of opportunities

$6.17 \pm 1.17$

CAI3- what I say is usually what I think

$5.65 \pm 1.18$

CAI6- even if people don't like me, I can still like them

$4.59 \pm 1.47$

CAI7- I'm easy to understand

$5.68 \pm 1.02$

CAI9- I'm willing to take the time to get to know people

$5.39 \pm 1.21$

CAl19- people think I'm a man of my word

$6.22 \pm 0.89$

CAI22-I find that everything has its meaning

$6.18 \pm 1.07$

CAI26 I really like myself

$5.48 \pm 1.17$

CAl30-I can accept all kinds of people

$4.54 \pm 1.48$

CAI31- when caring for others, I never hide my feelings

$5.03 \pm 1.34$

CAI33-I can express my feelings to others in a warm and caring way

$5.46 \pm 1.19$

CAI34- I love talking to people

$5.37 \pm 1.3$

CAI35-I think I'm sincere in dealing with others

$6.14 \pm 0.89$

CAI36- people need private space to think and feel

$6.36 \pm 0.87$

\section{Courage}

$58.71 \pm 11.07(4.52 \pm$

$0.85)$

CAI4- there's nothing I can do for a desperate person

$4.26 \pm 1.63$

CAI8- in terms of what I need to know, I already know enough

$5.05 \pm 1.51$

CAl11- I can't make life better

$5.55 \pm 1.44$

CAI12-I often feel uneasy when others depend on me

$5.23 \pm 1.48$

CAl13-I don't want to interrupt my business to help others

$4.93 \pm 1.47$

CAl14- it's hard for me to express my feelings when I get along with others

$5.01 \pm 1.53$

CAI15-I only care about doing things right, no matter what they say

$5.03 \pm 1.65$

CAl16-I find it hard to understand people without similar experiences

$4.84 \pm 1.59$

CAI23-I find it hard to understand people without similar experiences

$3.22 \pm 1.66$

CAI25- I'm not willing to make promises I can't fulfill

$2.02 \pm 1.18$ 
CAI28- new experiences often frighten me

CAI29- I'm afraid to let others know me publicly

CAI32- I don't like people asking me for help

Patience
$4.19 \pm 1.59$

$4.23 \pm 1.59$

$5.15 \pm 1.33$

$60.81 \pm 5.35(6.08 \pm$

$0.54)$

$6.75 \pm 0.75$

$6.63 \pm 0.66$

$4.96 \pm 1.44$

$6.31 \pm 0.91$

$6.44 \pm 0.8$

CAI18- I think it's important to respect and accept the opinions and feelings of others

CAI20-I think it's important to respect and accept the opinions and feelings of others

CAI21- good friends should take care of each other

$6.54 \pm 0.74$

CAI24- I like to encourage people

$5.93 \pm 1.01$

CAI27- I can see everyone's strengths and weaknesses

$5.24 \pm 1.19$

CAI37- it's easy for people to get along with me at any time

$5.48 \pm 1.17$

Total score

$197.77 \pm 20.3(5.35 \pm$

$0.55)$

\section{Emotional intelligence}

\section{Self-emotion assessment and expression}

WLEIS1- usually I know why I feel something $23.06 \pm 3.63(5.76 \pm$ $0.91)$

WLEIS2- I know my emotions very well

$5.74 \pm 1.01$

WLEIS3- I really understand how I feel

$5.75 \pm 1.03$

WLEIS4- I often know why I feel happy or unhappy

$5.77 \pm 1.01$

\section{Self-emotion management}

$5.8 \pm 1.06$

$19.91 \pm 4.61(4.98 \pm$ 1.15)

WLEIS5- when I encounter difficulties, I can control my temper and solve problems rationally

$5.12 \pm 1.22$

WLEIS6- I can control my emotions

$4.97 \pm 1.29$

WLEIS7- when I'm angry, I usually calm down in a short time

$4.95 \pm 1.31$ 
WLEIS8- I have great control over my emotions

$4.86 \pm 1.34$

Use of self emotion

$20.84 \pm 4.08(5.21 \pm$

1.02)

WLEIS9-I usually set goals for myself and try to achieve them

$5.11 \pm 1.25$

WLEIS10- I often tell myself that I am a very capable person

$4.9 \pm 1.24$

WLEIS11- I am a person who can encourage myself

$5.42 \pm 1.15$

WLEIS12-I always encourage myself to be the best

$5.41 \pm 1.15$

Emotion recognition of others

$20.41 \pm 4.26(5.21 \pm$

1.02)

WLEIS13- I can usually guess a friend's or colleague's mood from their behavior

$5.17 \pm 1.13$

WLEIS14- I have a strong ability to observe other people's emotions

$5.11 \pm 1.2$

WLEIS15- I have a keen insight into other people's feelings and emotions

$5.12 \pm 1.18$

WLEIS16- I know the emotions of people around me

$5.01 \pm 1.15$

Total score

$84.21 \pm 13.48(5.26 \pm$ $0.84)$

Table 3. Evaluation grade of caring ability of international norm nurses

\begin{tabular}{|llll|}
\hline Scale dimensions & High & Medium & Low \\
\hline Total score & $>220.30$ & $220.30 \sim 203.10$ & $<203.10$ \\
knowing & $>83.040$ & $83.04 \sim 63.40$ & $<63.40$ \\
Courage & $>69.740$ & $69.74 \sim 48.88$ & $<48.88$ \\
Patience & $>64.680$ & $64.88 \sim 52.34$ & $<52.34$ \\
\hline
\end{tabular}

\section{Socio-demographic characteristics}

Comparison of CAI and WLEIS scores in different socio-demographic characteristics

The results showed that the CAI score was higher in females than in males. The CAI and WLEIS scores of those students who chose their own major were higher due to the fact that they chose their own major compared to other reasons. The CAI and WLEIS scores of those who had received more comprehensive and in-depth humanistic care training were higher than those who did not. The CAl scores of those who participated in volunteer service activities were higher than those who did not. The WLEIS score of the pediatric staff was higher than that of the outpatient and emergency staff, and the differences were statistically significant $(P<0.05)$. There was no significant difference between CAI and WLEIS scores of other demographic characteristics (Table 4). 
Table 4. Comparison of CAI and WLEIS scores of hospital employees with different socio-demographic characteristics (score区) 
Variables

CAI WLEIS

score $t / F \quad P \quad$ score $\quad t / F \quad P$

Gender

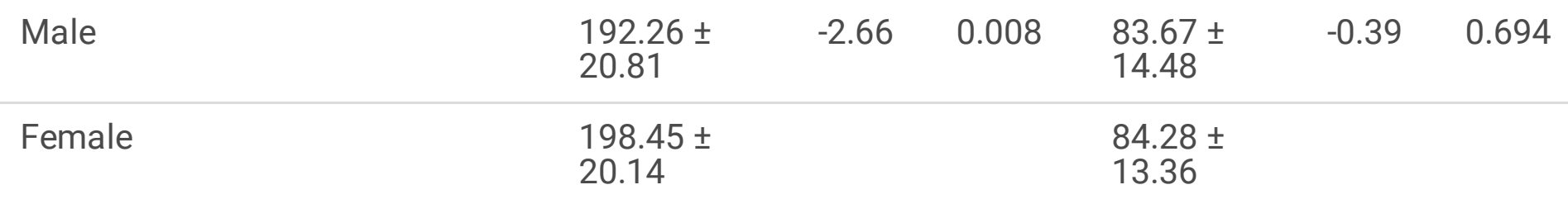

Department

Pediatrics

$199.73 \pm$

19.52

$1.1 \quad 0.354$

$86.38 \pm$

2.71

0.029 $12.95^{\mathrm{a}}$

Obstetrics and Gynecology

Department

$197.32 \pm$

18.89

$83.88 \pm$

13.28

Emergency clinic

$195.02 \pm$

21.22

$81.77 \pm$

$13.94^{\mathrm{a}}$

Medical Technology Department

$197.31 \pm$

22.31

$83.78 \pm$

13.87

other

$198.09 \pm$

19.39

$82.63 \pm$

13.30

Reasons for choosing this major

Self interest

Easy to find a job

Suggestions from family or

others

other

Have you received training on

humanistic care

No relevant training

Less training

More comprehensive and in-

depth
$200.66 \pm$

$21.23^{\mathrm{ab}}$

$195.25 \pm$

$18.84^{\mathrm{a}}$

$196 \pm$

$19.32^{b}$

$196.82 \pm$

23.58
$3.41 \quad 0.017$

$86.41 \pm$ $13.68^{\mathrm{abc}}$

$82.8 \pm$

$14.96^{\mathrm{a}}$

$82.99 \pm$ $12.65^{\mathrm{b}}$

$80.54 \pm$

$14.37^{\mathrm{C}}$

Have you ever participated in 
volunteer service

\begin{tabular}{|c|c|c|c|c|c|c|}
\hline No & $\begin{array}{l}194.38 \pm \\
21.09\end{array}$ & -2.83 & 0.005 & $\begin{array}{l}82.73 \pm \\
13.27\end{array}$ & -1.86 & 0.063 \\
\hline yes & $\begin{array}{l}199.03 \pm \\
19.86\end{array}$ & & & $\begin{array}{l}84.76 \pm \\
13.53\end{array}$ & & \\
\hline
\end{tabular}

Note: LSD method was used for pairwise comparison, with the same superscript, the difference between the two groups was statistically significant $(P<0.05)$.

Correlation analysis of hospital staff CAI and WLEIS score

Pearson correlation analysis showed that there was a positive correlation between the total score of emotional intelligence, self-emotion evaluation and expression, self-emotion management, self-emotion application, other's; emotion recognition and HCA of hospital staff $(P<0.001)$ (Table 5).

Table 5. Correlation Analysis of hospital staff CAI and WLEIS score $(n=769)$

\begin{tabular}{|c|c|c|c|c|}
\hline Items & knowing & Courage & Patience & CAl Total score \\
\hline \multicolumn{5}{|c|}{ Self-emotion assessment and expression } \\
\hline$r$ & 0.622 & 0.253 & 0.561 & 0.585 \\
\hline$P$ & $<.0001$ & $<.0001$ & $<.0001$ & $<.0001$ \\
\hline \multicolumn{5}{|c|}{ Self-emotion management } \\
\hline$r$ & 0.567 & 0.234 & 0.343 & 0.491 \\
\hline$P$ & $<.0001$ & $<.0001$ & $<.0001$ & $<.0001$ \\
\hline \multicolumn{5}{|c|}{ Use of self emotion } \\
\hline$r$ & 0.687 & 0.256 & 0.459 & 0.592 \\
\hline$P$ & $<.0001$ & $<.0001$ & $<.0001$ & $<.0001$ \\
\hline \multicolumn{5}{|c|}{ Emotion recognition of others } \\
\hline$r$ & 0.535 & 0.185 & 0.396 & 0.463 \\
\hline$P$ & $<.0001$ & $<.0001$ & $<.0001$ & $<.0001$ \\
\hline \multicolumn{5}{|c|}{ WLEIS Total score } \\
\hline$r$ & 0.739 & 0.284 & 0.533 & 0.651 \\
\hline$P$ & $<.0001$ & $<.0001$ & $<.0001$ & $<.0001$ \\
\hline
\end{tabular}


The results of this study show that the development of internal factors of emotional intelligence of hospital staff was unbalanced, the HCA was at a low level, and emotional intelligence was positively correlated to HCA. Among these factors, the ability of humanistic care was $(197.77 \pm 20.3)$, which was lower than the international norm, but higher than that reported by Xu et al. (20), Chi et al. (26), Ge et al. (16), and Zhao et al. (17). The CAI score was lower than the international norm, which was related to different cultural backgrounds and educational systems. In traditional Chinese culture, care may only occur in intimate relationships, while medical staff's care for patients is implicit. The low total average score of CAI was either related to the idea of "emphasizing technology and skills, neglecting service and humanistic care," or to medical education. However, Western medical education is known to pay more attention to practical education for students, which might have led to lower CAl score in this study than the international norm.

In this study, the average score of each dimension of CAI from high to low was knowing, patience and courage, which indicated that the staff of our hospital had a relatively good understanding of themselves, others and the surrounding environment. Also, their patience and resilience were similar to the research results of Wessel (36), and similar to the research results of Xu T (20) with regards to knowing and patience, and the score of courage was significantly higher than that of Xu T (20). The scores of understanding and patience, and the total score of this study were higher than those of $\mathrm{He}$ et al. (37). These differences were probably related to the fact that $\mathrm{Xu} T$ and $\mathrm{He} \mathrm{J}$ only studied nurses, while in this study, apart from nurses, other non-nurse staff also participated in the study. Caring is multidimensional, and caring behavior can be taught and learned (28). Therefore, teaching and training are needed to improve the ability of humanistic care. In recent years, domestic medical colleges and universities have gradually realized this problem and have gradually strengthened the construction of medical students' HCA. The HCA of the on-the-job hospital staff also needs teaching and training. We can perform humanistic teaching activities closely combined with clinical practice through the design and training of the knowledge structure construction module of humanistic medicine to help the hospital staff improve their medical humanistic knowledge structure, communication ability, and HCA. Arveklev (38) used improvisation, role play, and forum drama to improve students' understanding of caring and explore the caring experience. These training forms could be used for reference.

The results of WLEIS showed that the total average score of emotional intelligence of hospital staff was (84.21 \pm 13.48$)$, higher than that of $Y u(39)$ and Wang et al. (40). The scores of each dimension from high to low were self-emotion assessment and expression, self-emotion application, others' emotion recognition and self-emotion management, which indicated that the development of internal factors of emotional intelligence of the hospital staff was unbalanced, and the ability of self-emotion management needed to be improved. Similar to the research results of Acosta Prado (34), the results showed that Colombian managers had a stronger ability to evaluate their own emotions and weaker ability to recognize the emotions of others'. Emotional intelligence is not innate (41). It can be improved by selflearning, environmental intervention, and other measures, which suggests that we can train the emotional intelligence of hospital staff, stimulate the internal emotions of individuals, and better understand and predict the emotions and behaviors of others. The training mode can include education courses, such as 
listening training, self-management, interpersonal communication, etc., regular organization of lectures on emotional intelligence. We should perform emotional experience activities and team psychological counseling, create a positive working environment, combine emotional intelligence training with medical professional characteristics, help hospital staff learn to relieve negative emotions in appropriate ways, use positive emotions to deal with various challenges, and better adapt to clinical work and social needs.

The results of this study showed that the HCA levels of women were higher than that of men, which was consistent with the results of several studies $(16,26)$. These results were related to women's higher patience, carefulness, empathy, and emotional sensitivity. The CAI and WLEIS scores of those who chose their own specialty because of their own interests were higher than those for other reasons. As an internal driving force, employees have different feelings and satisfaction in work, and have stronger ability to overcome difficulties. Those who chose their own specialty and occupation voluntarily had a greater sense of professional value and are more willing to express concern for patients. Therefore, stimulating employee's interest and love for their own work could improve their HCA and emotional intelligence. The results showed that the CAI and WLEIS scores of those who had received more comprehensive and indepth humanistic care training were higher than the scores of those who had not. Luo songna's study (42) showed that emotional intelligence training for clinical nurses was helpful in improving the emotional intelligence of trainees, and the results of this study were consistent with those of previous studies. In addition, the results of this study showed that the CAl scores of those who had participated in volunteer service activities were higher than those who had not. Most of those who were willing to participate in volunteer service were dedicated, and most of them were willing to provide humanistic care for others. Additionally, cooperation with social organizations, recruitment of volunteers, and care training were the ongoing work in some hospitals. Volunteers might have received relevant training in their activities and experienced the atmosphere of humanistic care; thus, their humanistic care scores were higher than those who did not participate $(16,26,42)$.

The results of WLEIS score showed that the score of pediatric staff was higher than that of outpatient and emergency staff. This was probably related to their long-term contact with pediatric patients, due to which, it was easier to stimulate the staff to care for children. In addition, pediatric staff work is not only for children or children without self-care ability, but also for their families. Due to the particularity of their work objects and the impact of work pressure, pediatric nurses pay more attention to the regulation of self-emotion, which might also be the reason why pediatric staff score was higher than other staff in WLEIS (43).

In the correlation analysis, the hospital staff's emotional intelligence was positively correlated with the HCA. The higher the emotional intelligence, the higher the HCA, which was consistent with the study of Chi et al. (26). Individuals with high emotional intelligence were more likely to observe and find the emotional changes of patients, family members and colleagues around them, and could establish a good interpersonal relationship with them. Individuals with low emotional intelligence were more self-centered, less aware of the feelings of people around them, and their performance of humanistic care was 
relatively poor (39). Emotional intelligence could stimulate the internal emotions of individuals into practical action, making their emotions into humanistic care for patients.

\section{Research limitations}

This study has several limitations. First, we only selected one hospital for investigation. Although this hospital was large-scale, high-grade, and representative of Southwest China, convenient sampling still limited the universality of the research results at home and abroad. Second, the cross-sectional design limited the inference of causality between variables; thus, it was better to conduct longitudinal research and further explore more targeted predictors of HCA.

\section{Implications for practice and future research}

The findings of this study had implications for practice and research. The overall level of HCA of hospital staff was relatively low. This highlighted the importance of developing and implementing training programs to improve the HCA and emotional intelligence of all hospital staff. At the same time, hospital leaders needed to strengthen the theoretical and practical education of humanistic care and improve the care awareness of hospital staff.

\section{Conclusion}

The development of internal factors of emotional intelligence of hospital staff is unbalanced, with low levels of HCA. Therefore, it is necessary to strengthen the emotional intelligence training of hospital staff to improve their HCA.

\section{Declarations}

\section{Ethics approval and consent to participate}

This study was approved by the hospital ethics committee, ethical approval number: medical research 2021 Lun approval No. 077. We did not collect any personal information (name, ID card, or contact information) during the survey, and all participants agreed to answer the questions.

\section{Consent for publication}

Not applicable.

\section{Availability of data and materials}


The datasets generated and/or analyzed during the current study are not publicly available due to privacy guidelines but are available from the corresponding author on reasonable request.

\section{Competing interests}

No conflict of interest has been declared by the authors.

\section{Funding}

There is no funding for this study.

\section{Authors' contributions}

JM conducted drafted the manuscript, participated in the design of the study and data analysis, WP conducted research design and data collection, JP participated in the questionnaire design. All authors are in agreement with the content of the manuscript.

\section{Acknowledgements}

All the authors would like to express their heartfelt thanks to all the hospital staff who participated in this study.

\section{References}

[1] Warelow P, Edward KL. Caring as a resilient practice in mental health nursing. International Journal of Mental Health Nursing. 2007;16(2):132-5.

[2] Chen Y. Caring Ability among Chinese Nursing Students: A Cross-sectional Study and Educational Intervention. Guangzhou: Southern Medical Univers. 2017.

[3] Chen YX, Liu H. Investigation on the cognition of knowledge structure of humanistic medicine. Medicine and philosophy. 2015;36 (2a): 20-3.

[4] Kovner C, Brewer C, Wu YW, Chen Y, Suzuki M. Factors associated with work satisfaction of registered nurses. Journal of Nursing Scholarship. 2006;38(1):71-9.

[5] Lv HJ, Han CX, Wang DJ. Meta analysis of the influence of leader's emotional intelligence on leadership effectiveness. Advance in psychological science Exhibition, 2018,26 (2): 204-220.

[6] Salovey P, Mayer JD. Emotional intelligence. Imagination Cognition and Personality. 1990;9(3):185211. 
[7] Landa JMA, López-Zafra E. The Impact of Emotional Intelligence on Nursing: An Overview. Psychology. 2010;1(1):50-8.

[8] Rochester S, Kilstoff K, Scott G. Learning from success: Improving undergraduate education through understanding the capabilities of successful nurse graduates. Nurse Education Today. 2005;25(3):181-8 [9]B ai JM. The Effect about positive and negative emotion, emotional intelligence to emotional labor strategies for medical students. Suzhou: Suzhou University. 2014.

[10] Weng HC. Does the physician's emotional intelligence matter? Impacts of the physician's emotional intelligence on the trust, patient-physician relationship, and satisfaction. Health Care Manage Rev. 2008;33(4):280-8.

[11] Weng HC, Steed JF, Yu SW, Liu YT, Hsu CC, Yu TJ, et al. The effect of surgeon empathy and emotional intelligence on patient satisfaction. Advances Health Sciences Education Theory Practice, 2011;16(5):591-600.

[12] Kim SH, Ko JK, Park JH. Effect of Emotional Intelligence on Patient-Physician Interaction Scores of Clinical Performance Examination. Korean J Med Educ. 2011;23(3):159-165.

[13] Wang XR, Wang MF, Li XX, Liang R. Influence of emotional intelligence on clinical communication ability of nursing interns. Nursing research. 2020;34 (11):1926-1929.

[14] Pu FF, Bai YH, Wang P, Zhou L, Guo XL. The application of emotional intelligence in the study of doctor-patient relationship. Medicine and philosophy. 2017;38 (1a):43-6.

[15] Yan YM, Gong M. Advances of emotional intelligence in nursing organizations. Journal of Shanghai Jiaotong University Medical Scienc. 2015;35 (2):268-271.

[16] Ge XH, Li JS, Chen HY. Analysis of humanistic care ability of medical students and its influencing factors. Shanghai Jiaotong University Medicine science. 2014;34(11):1672-7.

[17] Zhao L, Zeng Y, Liao L, Wang SM, Yang YH, Xia YP, et al. Path analysis of the influence of empathy and interpersonal communication on humanistic care ability among undergraduate nursing students. Nursing Research. 2019;33(16):2759-2762.

[18] Simmons PR, Cavanaugh SH. Relationships among student and graduate caring ability and professional school climate. Journal of Professional Nursing Official Journal of the American Association of Colleges of Nursing. 2000;16(2):76-83.

[19] Hables RM. Factors Associated with Caring Abilities Among Nurses Working at El-Shatby Maternity University Hospital. Journal of American Science. 2013;9(2):387-394. 
[20] Xu T, Wang Y, Wang R, Lamb KV, Ren D, Dai G, et al. Predictors of caring ability and its dimensions among nurses in China: A cross-sectional study. Scandinavian Journal of Caring Sciences. 2020;1-14.

[21] Barrera L, Carrillo GM, Chaparro L, Pinto N, Rodríguez A, Sánchez B. Effect of the Program «Caring for caretakers»: Findings of a multicenter study. Colombia Médica. 2011;42(2 supl 1):35-44.

[22] Cho S, Drasgow F, Cao M. An Investigation of Emotional Intelligence Measures Using Item Response Theory. Psychological Assessment. 2015;27(4):1241.

[23] Hiroshi T, Kohsuke Y. Development of a Japanese version of Wong and Law Emotional Intelligence Scale. Bulletin of Center for Educational Research and Development. 2011;7-12.

[24] Li TW, Saklofske DH, Bowden SC, Yan GG, Fung TS. The Measurement Invariance of the Wong and Law Emotional Intelligence Scale (WLEIS) Across Three Chinese University Student Groups From Canada and China. Journal of Psychoeducational Assessment. 2012;30(4):439-452.

[25] Wan S, Noor M. Examining the Psychometric Properties of the Wong and Law Emotional Intelligences Scale (WLEIS)_1. Journal of social sciences and humanities. 2015; 2:81-90.

[26] Chi Y, Wang JJ, Li HY. Intermediary Effect of Emotional between Empathy and Humanistic Care of Nursing Students. Nurs J Chin PLA. 2020;37(9):22-5.

[27] Guo T, Sui SJ, Yu F, Yao HB. Research progress of nurses' emotional intelligence training. Journal of nursing education. 2015;30(5):424-6.

[28] Cunha M, Duarte J, Cardoso A, Ramos A, Almeida V. Caregiver skills inventory: factorial structure in a sample of portuguese participants. Millenium-Journal of Education Technologies and Health. 2018;6:4155.

[29] Douglas K. When caring stops, staffing doesn't matter: part II. Nursing Economic. 2011;29(3):145-7.

[30] Ma YL. The research of human caring capacity and influence factors of nursing undergraduates. Bengbu: Bengbu Medical College. 2012.

[31] Wong CS, Law KS, Wong PM. Development and validation of a forced choice emotional intelligence measure for Chinese respondents in Hong Kong. Asia Pacific Journal of Manageme. 2004;21(4):535-559.

[32] Rodrigues N, Rebelo T, Coelho JV. Adaptation of the Wong and Law Emotional Intelligence Scale (WLEIS) and analysis of its factorial structure and reliability in a Portuguese sample. Psychologica. 2011; (55):189-207.

[33] Fukuda E, Saklofske DH, Tamaoka K, Lim H. Factor structure of the Korean version of Wong and Law's Emotional Intelligence Scale. Assessment. 2012;19(1):3-7. 
[34] Acosta-Prado JC, Torres R, Torres G. Characterization of Emotional Intelligence in Colombian Managers. Universitas Psychologica. 2015;14(3):815-832.

[35] Chen SR, Zhang HM, Sun YS, Liang DD. The investigation on influential factors of humanistic caring ability in nurses receiving standard training. Nursing of Integrated Traditional Chinese and Western Medicine. 2018;4 (4):86-9.

[36] Wessel J, Larin H, Benson G, Brown B, Ploeg J, Williams R, et al. Emotional-Social Intelligence in Health Science Students and its Relation to Leadership, Caring and Moral Judgment. The Internet Journal of Allied Health Science and Practice. 2008;1:1-9.

[37] He J, Hu DY, Liu YL, Wu LF, Liu L. Study of the effect of humanistic nursing care model wards in Children Caring Ward School on the nurses' caring ability. Chinese Nursing Research. 2016;3(1):45-7.

[38] Arveklev SH, Wigert H, Berg L, Burton B, Lepp M. The use a application of drama in nursing education-an integrative review of the literature. Nurse Educ Today. 2015;5:12-7.

[39] Yu HX. Study on the correlation between emotional intelligence, coping style and job burnout of junior nurses. Nanchang: Nanchang University. 2019.

[40] Wang YY, Liu H, Yuan LP, Wang GQ, Ye N, Jiang HJ, et al. Study on the correlation between nurses' humanistic care ability and emotional labor and emotional intelligence. Journal of Qiqihar Medical University. 2019;40 (1):103-106.

[41] Foji S, Vejdani M, Salehiniya $\mathrm{H}$, Khosrorad RH. The effect of emotional intelligence training on general health promotion among nurse. J Educ Health Promot,2020,9(1):4.

[42] Luo SN, Hu YH, Wang HP, Pan XY. Effect of emotional intelligence training on Job Burnout of clinical nurses. Nursing and Rehabilitation. 2020;19(12):79-82.

[43] Tai MG, Yang X, Guo L, Gao F, Wang K, Wu ZZ, et al. A study on the relationship between conflict management model and emotional intelligence of pediatric nurses in tertiary grade A hospitals. Chinese Nursing management. 2017;17(5):650-654. 